\title{
Astigmatism induced by conventional spherical ablation after PRK and LASIK in myopia with astigmatism $<1.00 \mathrm{D}$
}

This article was published in the following Dove Press journal:

Clinical Ophthalmology

19 December 2012

Number of times this article has been viewed

\author{
Steven M Christiansen' \\ Mark D Mifflin' \\ Jason N Edmonds' \\ Rachel G Simpson ${ }^{2}$ \\ Majid Moshirfar' \\ 'John A Moran Eye Center, University \\ of Utah, Salt Lake City, UT, ${ }^{2}$ The \\ University of Arizona College \\ of Medicine, Phoenix, AZ, USA
}

Background: The purpose of this study was to evaluate surgically-induced astigmatism after spherical ablation in photorefractive keratectomy (PRK) and laser-assisted in situ keratomileusis (LASIK) for myopia with astigmatism $<1.00 \mathrm{D}$.

Methods: The charts of patients undergoing spherical PRK or LASIK for the correction of myopia with minimal astigmatism of $<1.00$ D from 2002 to 2012 at the John A Moran Eye Center in Salt Lake City, UT, were retrospectively reviewed. Astigmatism was measured by manifest refraction. The final astigmatic refractive outcome at 6 months postoperatively was compared with the initial refraction by Alpins vector analysis.

Results: For PRK, average cylinder increased from $0.39 \pm 0.25(0.00-0.75)$ preoperatively to $0.55 \pm 0.48(0.00-1.75)$ postoperatively $(P=0.014)$, compared with an increase in LASIK eyes from $0.40 \pm 0.27(0.00-0.75)$ preoperatively to $0.52 \pm 0.45(0.00-2.00)$ postoperatively $(P=0.041)$. PRK eyes experienced an absolute value change in cylinder of $0.41 \pm 0.32$ $(0.00-1.50)$ and LASIK eyes experienced a change of $0.41 \pm 0.31(0.00-1.50, P=0.955)$. Mean surgically-induced astigmatism was $0.59 \pm 0.35(0.00-1.70)$ in PRK eyes, with an increase in surgically-induced astigmatism of $0.44 \mathrm{D}$ for each additional $1.00 \mathrm{D}$ of preoperative cylinder; in LASIK eyes, mean surgically-induced astigmatism was $0.55 \pm 0.32(0.00-1.80, P=0.482)$, with an increase in surgically-induced astigmatism of $0.29 \mathrm{D}$ for each $1.00 \mathrm{D}$ of preoperative cylinder.

Conclusion: Spherical ablation can induce substantial astigmatism even in eyes with less than one diopter of preoperative astigmatism in both PRK and LASIK. No significant difference in the magnitude of surgically-induced astigmatism was found between eyes treated with PRK and LASIK, although surgically-induced astigmatism was found to increase with greater levels of preoperative astigmatism in both PRK and LASIK.

Keywords: surgically-induced astigmatism, ablation, photorefractive keratectomy, laser-assisted in situ keratomileusis

\section{Introduction}

Excimer laser ablation to correct myopia has been available for over two decades, demonstrating good results for mild and moderate myopia with both photorefractive keratectomy (PRK) and laser-assisted in situ keratomileusis (LASIK). Initially, laser systems were not capable of correcting astigmatism. Many refractive surgeons ignored astigmatic errors less of than one diopter, assuming that spherical myopic ablation by excimer procedures was essentially neutral from an astigmatic standpoint, similar to the traditional surgical planning for radial keratotomy. However, the previous assumption that astigmatism less than one diopter will resolve with spherical ablation may not be accurate. Several studies have described changes after spherical
Correspondence: Majid Moshirfar 65 Mario Capecchi Drive, Salt Lake City, UT 84I32, USA

Tel + I 80I 58I 2352

Fax + I 80I 58I 3357

Email majid.moshirfar@hsc.utah.edu 
excimer ablation in which either a spherical refractive error before laser was replaced with a new astigmatic error, or an astigmatic error underwent a change in power and/or axis. ${ }^{1-4}$ Additional studies have provided vector analysis in PRK for myopia, myopia with astigmatism, and hyperopia, although no studies to date have provided vector analysis comparing spherical ablation in PRK and LASIK. ${ }^{5}$ In this report, we describe our experience with spherical ablation in both PRK and LASIK for patients with myopia and astigmatism $<1.00 \mathrm{D}$ by providing a vector analysis according to the Alpins method. ${ }^{6,7}$

\section{Materials and methods}

The charts of patients undergoing spherical PRK or LASIK for the correction of myopia with minimal astigmatism of $<1.00$ D from 2002 to 2012 at the John A Moran Eye Center in Salt Lake City, UT, were retrospectively reviewed. All eyes were targeted for emmetropia, treated with the VISX Star S3/S4 excimer laser platform (Abbott Medical Optics Inc/VISX Inc, Irvine, CA), had received no prior eye surgeries, and had follow-up of at least 6 months. All eyes had preoperative cylinder $<1.00 \mathrm{D}$ measured by manifest refraction, and were screened topographically for asymmetry between eyes, nonorthogonal bow ties, inferior steepening, or skewed radial axes using either the Orbscan IIz (Bausch and Lomb, Rochester, NY), the Pentacam (Oculus, Wetzlar, Germany) or the Atlas (Carl Zeiss Meditec Inc, Dublin, CA). During the time frame of this study, the topography devices used at our institution to screen for refractive surgery patients have evolved with the advancement of technology. All corneal K values included in this study were measured preoperatively and postoperatively using the Atlas corneal topographer, and therefore only the Atlas keratometry data were utilized for this study, because it was the only platform present over the entire period of data analysis. Due to incongruities between the axis of astigmatism measured by topography compared with manifest refraction or due to the patient's inability to notice subjective improvement when the astigmatic correction was added to the intended spherical correction during preoperative refraction, the decision was made to proceed with conventional, nontoric spherical laser ablation.

Photorefractive keratectomy or LASIK was performed by two surgeons (MM, MDM) using a $193 \mathrm{~nm}$ excimer beam generated within the VISX Star S3/S4 excimer laser and delivered at $8 \mathrm{~Hz}$ with a fluence of $180 \mathrm{~mJ} / \mathrm{cm}^{2}$. All eyes had an optical zone of $6.5 \mathrm{~mm}$ with blend to $8.0 \mathrm{~mm}$. In the PRK group, 31 eyes (50\%) had mechanical debridement and $31(50 \%)$ had transepithelial ablation. Patients received a bandage contact lens with fluoroquinolone and prednisolone acetate $1 \%$ drops four times daily for the first week. Afterwards, the bandage contact lens and antibiotic drops were discontinued and the prednisolone acetate $1 \%$ was continued twice for the first month. The patient's steroid was then changed to fluorometholone $0.1 \%$ and a slow steroid taper was conducted ending at postoperative month 3. Postoperative follow-up was performed routinely on days 1 and 4, and at months 1, 3, and 6 postoperatively. For LASIK procedures, superiorly hinged lamellar flaps were created with a Hansatome microkeratome (Bausch and Lomb Surgical, Rochester, NY) using a $160 \mu \mathrm{m}$ plate and $9.0 \mathrm{~mm}$ ring until August 2006. From September 2006 to the present, flaps were created with the IntraLase $60 \mathrm{kHz}$ femtosecond laser (Abbott Medical Optics Inc), with a flap diameter of $9.0 \mathrm{~mm}$ and a flap thickness of $110 \mu \mathrm{m}$. Following LASIK ablation, the flap was replaced in all patients, and any patients with complications were eliminated from the dataset.

LASIK patients received fluoroquinolone and prednisolone acetate $1 \%$ drops four times daily until postoperative week 1 . Postoperative follow-up was routinely performed at day 1 and at months 1,3 , and 6 postoperatively. Manifest refraction at 6 months postoperatively was compared with preoperative refraction using an outcome analysis program (Sight Tracker, Medical Outlook Inc, Salt Lake City, UT). Both manifest refractions and induced astigmatic calculations were reported in the spectacle plane. The absolute value change in astigmatism was calculated as $\mid$ cylinder $_{\text {postop }}-$ cylinder $_{\text {preop }} \mid$, the absolute value change in axis was calculated as $\mid$ axis $_{\text {postop }}-$ axis $_{\text {preop }} \mid$, and mean differences were compared. Vector analysis was performed according to the method described by Alpins. ${ }^{6,7}$ Differences between PRK and LASIK were analyzed using a paired, twotailed Student's $t$-test and a two-tailed Z-test for proportions.

\section{Results}

A total of 62 eyes in 48 patients had nontoric spherical PRK, and 72 eyes in 51 patients had nontoric spherical LASIK. Table 1 demonstrates the preoperative and postoperative patient and refractive characteristics. The mean preoperative spherical equivalent in PRK eyes was $-4.97 \pm 1.90(-1.25$ to -8.25$)$, which was significantly different from the mean preoperative spherical equivalent in LASIK eyes of $-6.19 \pm 1.93(-3.50$ to $-13.00, t$-test, $P<0.001)$. The mean preoperative cylinder in PRK eyes was $0.39 \pm 0.25(0.00-0.75)$, which was not significantly different from the mean preoperative cylinder in LASIK eyes of $0.40 \pm 0.27(0.00-0.75$, $t$-test, $P=0.831)$. In PRK eyes, the mean postoperative spherical equivalent was $-0.49 \pm 0.73(-2.50-1.25)$, which was not significantly different 
Table I Preoperative characteristics and vector analysis

\begin{tabular}{|c|c|c|c|}
\hline Patient characteristics & PRK & LASIK & \\
\hline Eyes & 62 & 72 & \\
\hline Male/female & $|7 / 3|$ & $27 / 24$ & \\
\hline Mean age & 39 & 40 & \\
\hline Preop characteristics & Mean \pm SD (range) & Mean \pm SD (range) & $P$-value \\
\hline Spherical equivalent (D) & $-4.97 \pm 1.90(-1.25$ to -8.25$)$ & $-6.19 \pm 1.93(-3.50$ to -13.00$)$ & $<0.001$ \\
\hline \multirow[t]{2}{*}{ Cylinder (D) } & $0.39 \pm 0.25(0.00$ to 0.75$)$ & $0.40 \pm 0.27(0.00$ to 0.75$)$ & 0.831 \\
\hline & PRK & LASIK & \\
\hline Postop characteristics & Mean \pm SD (range) & Mean \pm SD (range) & $P$-value \\
\hline Spherical equivalent (D) & $-0.49 \pm 0.73(-2.50$ to 1.25$)$ & $-0.44 \pm 0.54(-2.50$ to 1.00$)$ & 0.647 \\
\hline Cylinder (D) & $0.55 \pm 0.48(0.00$ to 1.75$)$ & $0.52 \pm 0.45(0.00$ to 2.00$)$ & 0.728 \\
\hline $\mid \Delta$ Cylinder $\mid(\mathrm{D})$ & $0.4 \mathrm{I} \pm 0.32(0.00$ to $\mathrm{I} .50)$ & $4 \mathrm{I} \pm 0.3 \mathrm{I}(0.00$ to $\mathrm{I} .50)$ & 0.955 \\
\hline $\mid \Delta$ axis $\mid$ (degrees) & $18.7 \pm 28.1(0.00$ to 125$)$ & $17.8 \pm 32.1$ (0.00 to 165$)$ & 0.863 \\
\hline Mean TIA & $0.20 \pm 0.13(0.00$ to 0.38$)$ & $0.20 \pm 0.14(0.00$ to 0.38$)$ & $0.77 I$ \\
\hline Mean SIA & $0.59 \pm 0.35(0.00$ to 1.70$)$ & $0.55 \pm 0.32(0.00$ to 1.80$)$ & 0.482 \\
\hline$S I A \geq 0.50 D$ & $60 \%$ & $73 \%$ & 0.738 \\
\hline$S I A \geq 0.75 D$ & $37 \%$ & $31 \%$ & 0.183 \\
\hline Coefficient of adjustment & $0.40 \pm 0.30(0.00$ to 1.44$)$ & $0.45 \pm 0.39(0.00$ to 2.05$)$ & 0.148 \\
\hline Index of success & $2.68 \pm 1.99(0.75$ to 9.67$)$ & $2.25 \pm 1.90(0.33$ to 7.55$)$ & 0.267 \\
\hline Angle of error (degrees) & $0.95 \pm 22.8(-52.5$ to 55.0$)$ & $-2.03 \pm 25.2(-70.0$ to 74.0$)$ & 0.478 \\
\hline
\end{tabular}

Abbreviations: LASIK, laser-assisted in situ keratomileusis; PRK, photorefractive keratectomy; SE, spherical equivalent; SD, standard deviation; D, diopters; $\mid \Delta$ Cylinder $\mid$, $\mid$ cylinder $_{\text {postop }}-$ cylinder $_{\text {preop }}|;| \Delta$ axis|, | |axis $_{\text {postop }}$ - axis preop $\mid$ SIA, surgically induced astigmatism; TIA, targeted induced astigmatism; Coefficient of Adjustment, TIA/SIA; Index of Success, Difference Vector/TIA.

from the mean postoperative spherical equivalent in LASIK eyes of $-0.44 \pm 0.54(-2.50-1.00, t$-test, $P=0.647)$. The mean postoperative cylinder in PRK eyes was $0.55 \pm 0.48(0.00-1.75)$, which was not significantly different compared with LASIK eyes of $0.52 \pm 0.45(0.00-2.00, t$-test, $P=0.728)$, and the mean absolute value of the change in cylinder in PRK eyes was $0.41 \pm 0.32(0.00-1.50)$, which was not significantly different from LASIK eyes where the mean absolute value of the change in cylinder was $0.41 \pm 0.31(0.00-1.50, t$-test, $P=0.955)$. The mean absolute value of the change in axis in PRK eyes was $18.7 \pm 28.1(0.00-125)$, which was also not significantly different from LASIK eyes, where the change in axis was $17.8 \pm 32.1$ $(0.00-165, t$-test, $P=0.863)$. Alpins' method of vector analysis was used to assess changes in refractive astigmatism, and the following variables of interest were calculated for analysis: targeted-induced astigmatism (TIA), surgically-induced astigmatism (SIA), coefficient of adjustment, index of success (IOS), angle of correction, and angle of error. ${ }^{9.10}$

\section{Targeted-induced astigmatism}

TIA is a vector representing the magnitude and direction of dioptric force required to achieve a desired astigmatic goal from a preoperative astigmatic state. In this study, the mean spherical equivalent at the corneal plane was the attempted correction, so TIA was desired to be one-half the magnitude of preoperative cylinder with no change in the axis of the
TIA vector. The mean TIA in PRK eyes was $0.20 \pm 0.13$ $(0.00-0.38)$, which was not significantly different to that in LASIK eyes of $0.20 \pm 0.14(0.00-0.38, t$-test, $P=0.771)$.

\section{Surgically-induced astigmatism}

SIA is a vector representing the magnitude and direction of the dioptric force that occurred in achieving the operative result from the preoperative astigmatic state. The mean SIA for PRK eyes was $0.59 \pm 0.35(0.00-1.70)$, which was not significantly different compared with LASIK eyes, where the mean SIA was $0.55 \pm 0.32(0.0-1.80, t$-test, $P=0.482)$. Sixty percent of eyes treated with PRK experienced SIA $\geq 0.50 \mathrm{D}$, which was not significantly different when compared with the $73 \%$ of LASIK eyes that had a SIA $\geq 0.50 \mathrm{D}$ (Z-test, $P=0.738)$. No significant difference was found in the percentage of eyes with SIA $\geq 0.75 \mathrm{D}$, where $37 \%$ of eyes treated with PRK had an SIA $\geq 0.75 \mathrm{D}$, compared with $31 \%$ in eyes treated with LASIK (Z-test, $P=0.183$ ).

In both PRK and LASIK (Figure 1), the magnitude of SIA increased with the amount of preoperative astigmatism. In PRK, the slope of the regression line was 0.44 , demonstrating that the mean SIA increased by $0.44 \mathrm{D}$ for each $1.00 \mathrm{D}$ increase of preoperative cylinder. In LASIK, the slope of the regression line was 0.29 , demonstrating that the mean SIA increased by $0.29 \mathrm{D}$ for every $1.00 \mathrm{D}$ increase in preoperative cylinder. For both PRK and LASIK, SIA did not appear to correlate with 


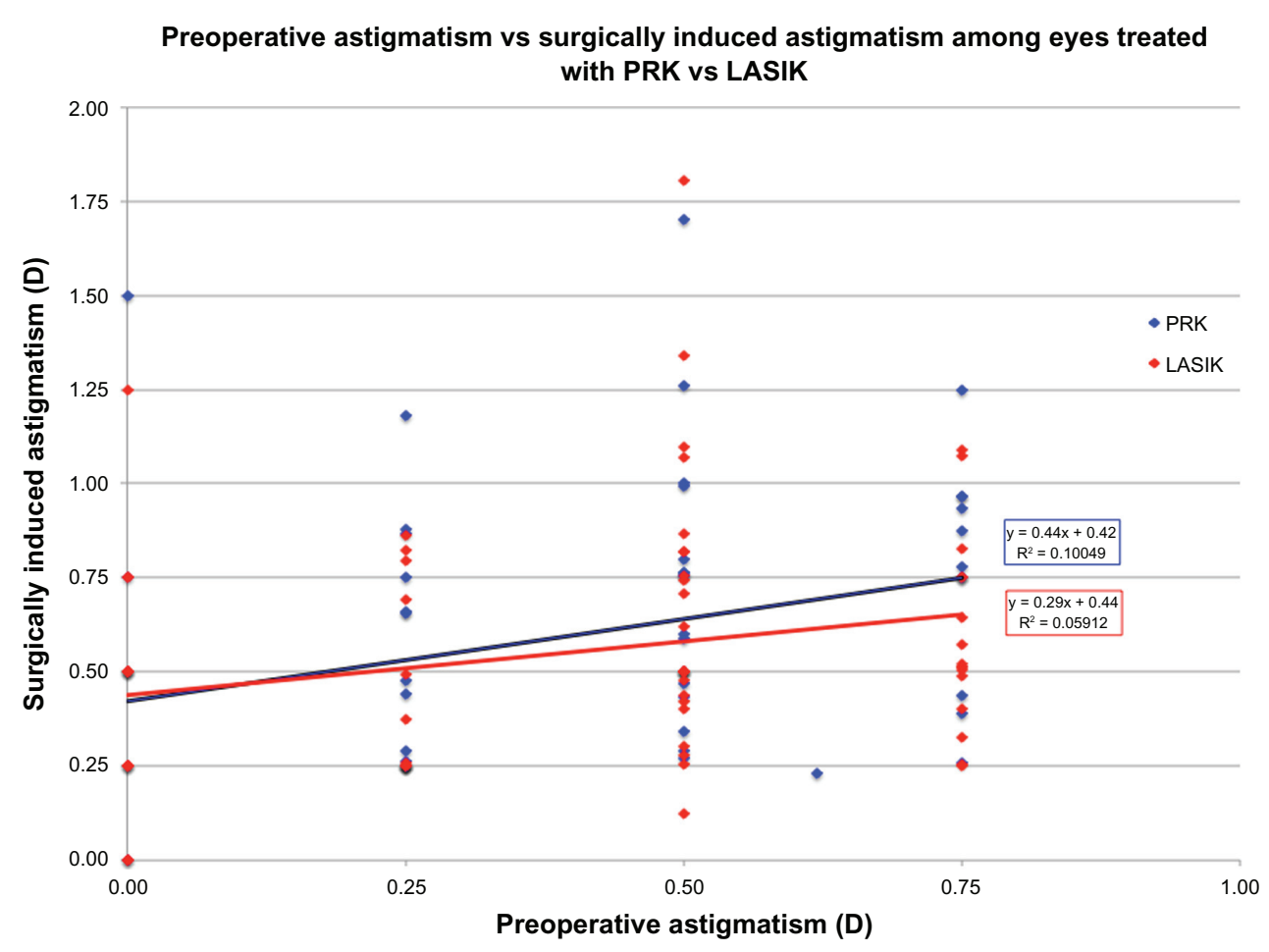

Figure I Preoperative astigmatism vs surgically induced astigmatism among eyes treated with PRK vs LASIK. Abbreviations: D, diopter; LASIK, laser-assisted in situ keratomileusis; PRK, photorefractive keratectomy.

the level of preoperative spherical equivalent (Figure 2); the mean SIA for PRK and LASIK increased by only $0.01 \mathrm{D}$ and $0.06 \mathrm{D}$, respectively, for each diopter of myopia.

\section{Coefficient of adjustment}

When the astigmatic goal fails to coincide with the achieved result, the SIA and TIA vectors do not coincide and may vary in magnitude, axis, or both. The coefficient of adjustment measures this error, and is defined as the ratio of the TIA to the SIA. The coefficient of adjustment is the coefficient required to adjust future astigmatism treatment magnitudes, and is ideally one, suggesting equal TIA and SIA. If the surgeon achieves an overcorrection, the coefficient of adjustment might be 0.8 (TIA < SIA), suggesting that the surgeon should have used $80 \%$ of what was actually selected. If the surgeon achieves an undercorrection, the coefficient of adjustment might be 1.2 (TIA > SIA), suggesting the surgeon should have used $120 \%$ of what was actually selected. Our results show an overcorrection in the magnitude of postoperative astigmatism in both PRK and LASIK eyes; $92 \%$ of PRK eyes and $90 \%$ of LASIK eyes had a coefficient of adjustment of less than 1, due to the larger value of SIA with respect to TIA (Figures 3 and 4).

\section{Index of success}

The IOS is determined by dividing the difference vector (DV) by the TIA (IOS = DV/TIA), where the DV is an absolute measure of success that describes the change in magnitude and axis that would enable the initial surgery to achieve the original target on the second attempt. Therefore, the IOS is essentially how far the target is missed divided by the original intended target. An IOS of zero indicates that the surgical goal has been met, because no second attempt would be needed and the DV would be equal to zero, making the IOS similarly equal to zero. If the index lies between zero and one, less than $100 \%$ success in correcting the astigmatism has been achieved. For example, an IOS value of 0.35 would indicate $65 \%$ success has been achieved in attaining the surgical goal, and correspondingly, an IOS value greater than one indicates a result worse than the preoperative state. In our analysis, the index of success for eyes treated with PRK was $2.68 \pm 1.99(0.75-9.67)$ and for LASIK was $2.25 \pm 1.90(0.33-7.55, t$-test, $P$ value $=0.267)$, indicating a worsening of the astigmatism postoperatively.

\section{Angle of correction}

The angle of correction is the angle between the targeted and postoperative astigmatism. In this study, the targeted cylinder axis was assumed to be the same as the preoperative cylinder. No significant difference was found between PRK and LASIK in the percent of eyes achieving an absolute difference in axis preoperatively to postoperatively of 


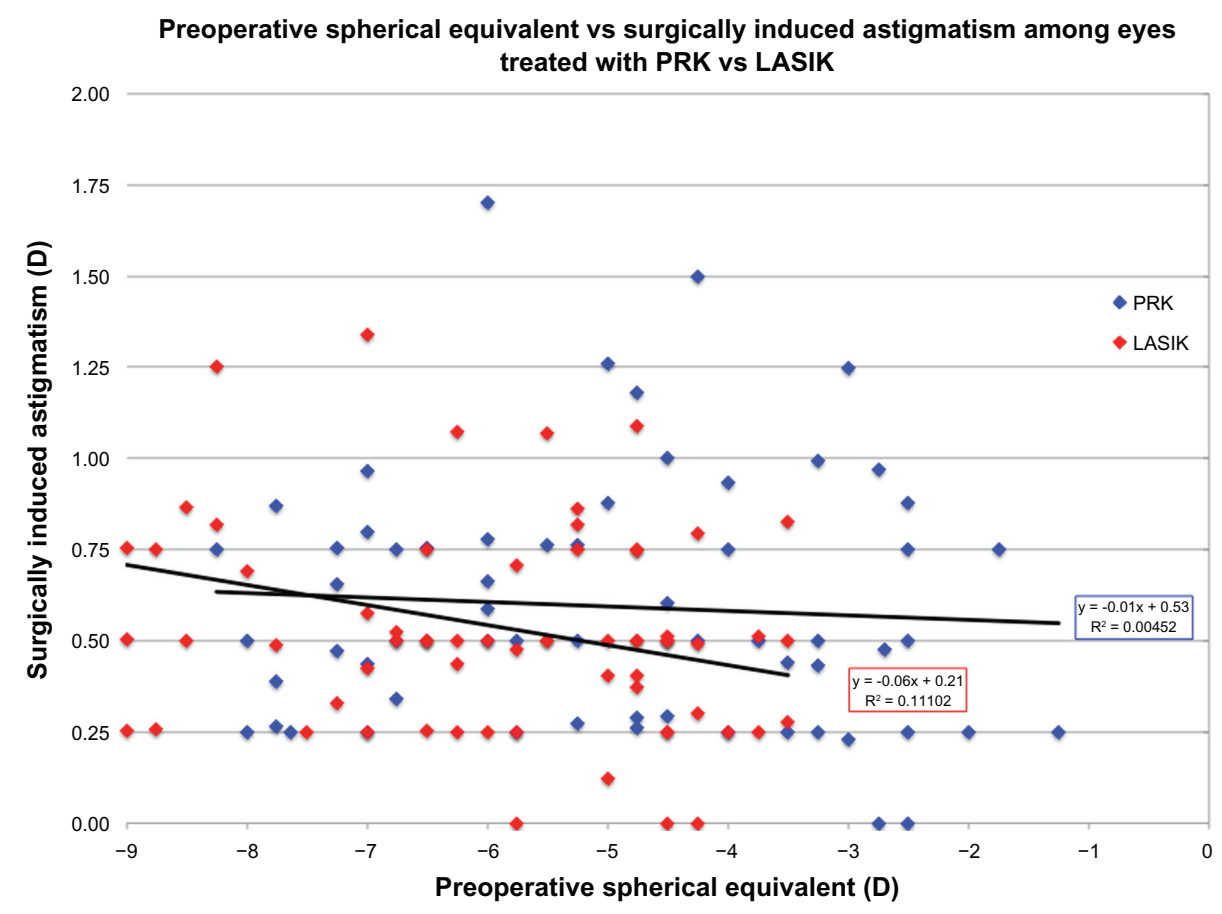

Figure 2 Preoperative spherical equivalent vs surgically induced astigmatism among eyes treated with PRK vs LASIK. Abbreviations: D, diopter; LASIK, laser-assisted in situ keratomileusis; PRK, photorefractive keratectomy.

$0-20^{\circ}$ (Z-test, $\left.P=0.600\right), 21-40^{\circ}$ (Z-test, $P=0.892$ ), $41-90^{\circ}$ (Z-test, $P=0.365$ ), and $91-180^{\circ}$ (Z-test, $P=0.774$, Figure 5). Although angle of correction is a measure of the final astigmatic result, it is not as useful as the angle of error in determining and comparing the success of reducing the astigmatism.

\section{Angle of error}

The angle of error is half the angle subtended on vector diagram by the TIA and SIA vector. It is a positive value when there has been a counterclockwise change and negative if the change is clockwise in the final postoperative cylinder axis. Mean angle of error was $0.95 \pm 22.8$ ( -52.5 to 55.0) for PRK

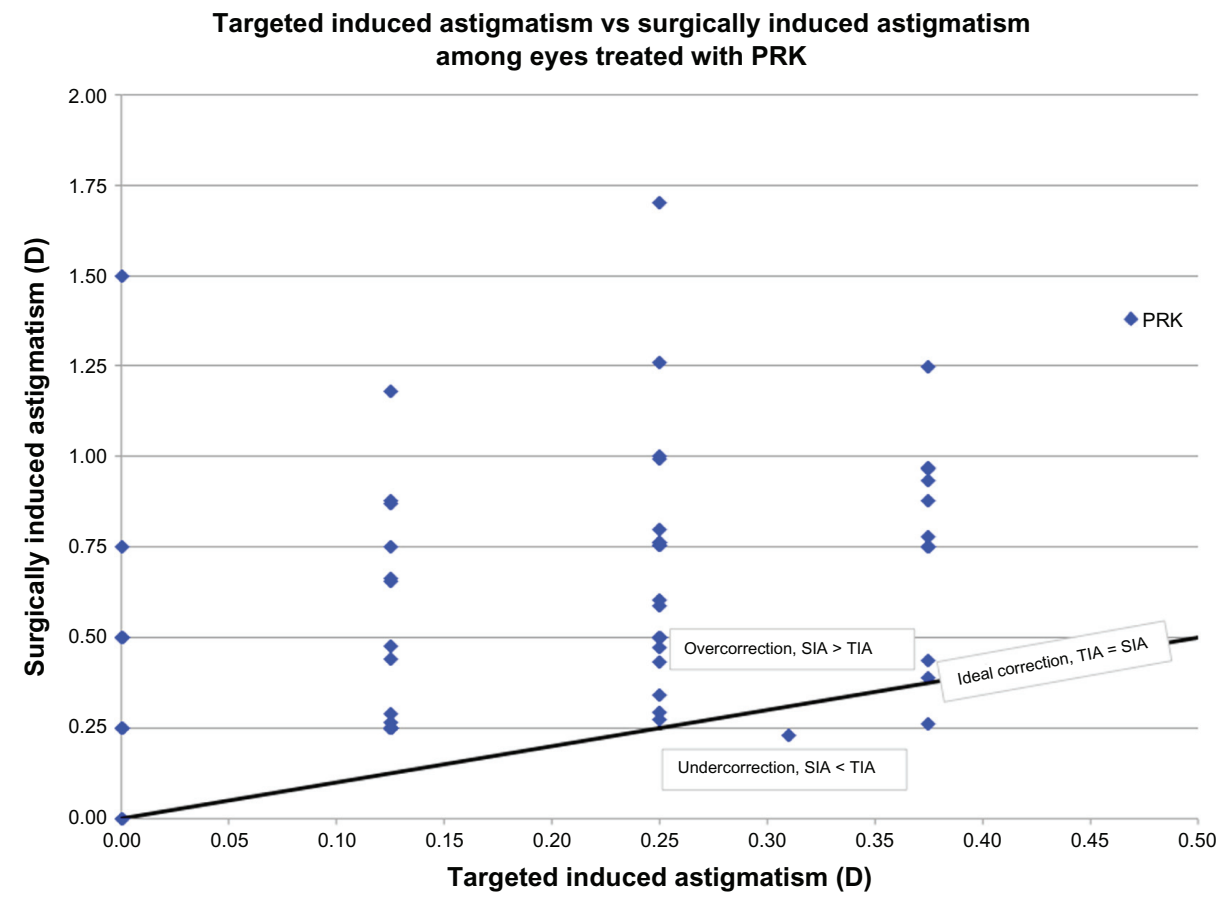

Figure 3 Targeted induced astigmatism vs surgically induced astigmatism among eyes treated with PRK.

Abbreviations: D, diopter; PRK, photorefractive keratectomy. 


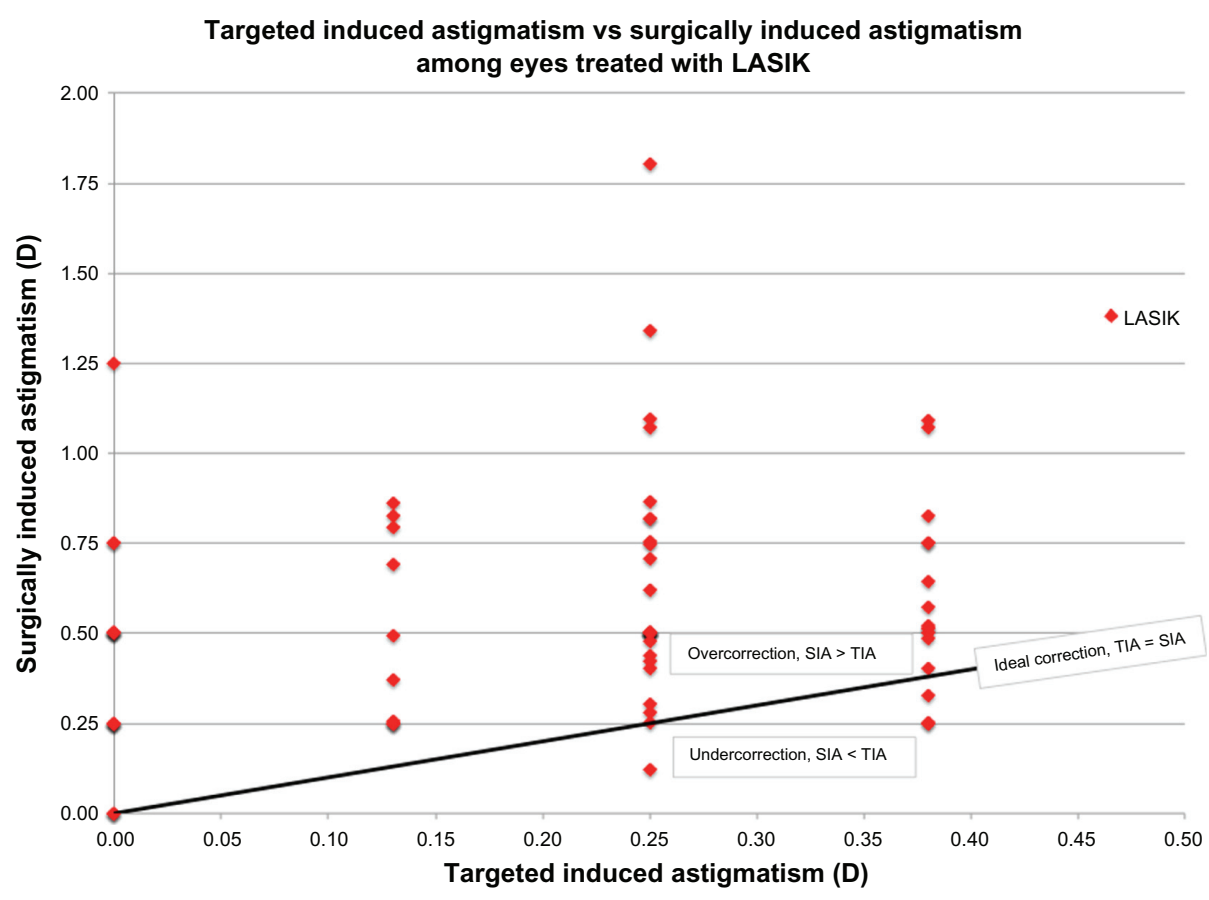

Figure 4 Targeted induced astigmatism vs surgically induced astigmatism among eyes treated with LASIK.

Abbreviations: D, diopter; LASIK, laser-assisted in situ keratomileusis.

eyes and $-2.03 \pm 25.2$ ( -70.0 to 74.0$)$ for LASIK eyes, with no significant difference found between the two treatments $(t$-test, $P=0.478)$. The magnitude of the angle of error was less than ten degrees in $61.3 \%$ of PRK eyes and $56.9 \%$ of LASIK eyes (Z-test, $P=0.610$ ), and was less than 20 degrees in $66.1 \%$ of PRK eyes and $62.5 \%$ of LASIK eyes (Z-test, $P=0.662$ ), with no significant difference between treatments.

\section{Discussion}

Effective modification and control of astigmatism has been a significant challenge in refractive surgery, and treatment of spherical myopia has historically been more predictable compared with correction of myopia with astigmatism. ${ }^{8}$ As previously mentioned, an astigmatic error of less than one diopter is often ignored when performing refractive surgery.

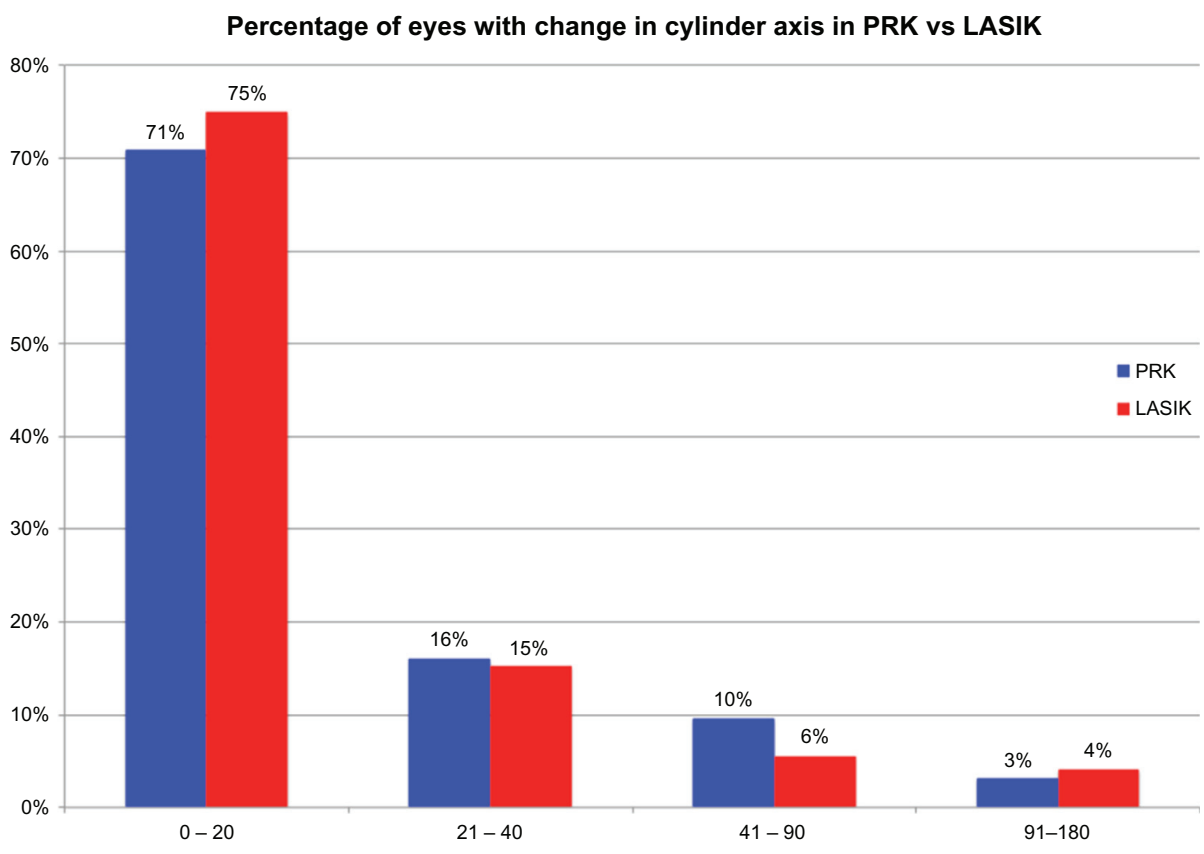

Figure 5 Percentage of eyes with change in cylinder axis in PRK vs LASIK.

Abbreviations: LASIK, laser-assisted in situ keratomileusis; PRK, photorefractive keratectomy. 
Studies by Simon et al and Löwenstein et al have separately claimed that spherical ablation after PRK can reduce the astigmatic component of refraction. ${ }^{9,10}$ When performing nontoric spherical ablation for PRK and LASIK, we were initially under the impression that spherical ablation would reduce or have no effect on the magnitude of cylinder. ${ }^{11}$ Targeted astigmatism was assumed to be one-half the magnitude of preoperative cylinder. Thus, we formulated our targeted astigmatic goal and then assessed the results. However, analysis of the variance between TIA and SIA for nontoric spherical ablation in both procedures revealed a consistent trend toward an increase in the magnitude of postoperative astigmatism with respect to preoperative astigmatism, wherein $85 \%$ of PRK eyes and $90 \%$ of LASIK eyes had an induction of postoperative cylinder (Figures 3 and 4).

Seiler et al reported that spherical PRK ablation can induce astigmatism of more than $0.75 \mathrm{D}$ in $2.5 \%$ of cases after one year, but no vector analysis was implemented. ${ }^{12}$ Shah et al analyzed the astigmatism induced after spherical PRK corrections for eyes with subjective preoperative cylinder of $\leq 2.5 \mathrm{D}$ and reported $11.1 \%$ of cases with more than $0.75 \mathrm{D}$ of induced astigmatism using Alpins vector analysis. ${ }^{4}$ In our study, $37 \%$ of PRK eyes and $31 \%$ of LASIK eyes showed an induced cylinder $\geq 0.75 \mathrm{D}$. In a study of 18 hyperopic eyes with a maximum cylinder of $-0.75 \mathrm{D}$, vector analysis found that the SIA was not significantly different between LASIK and PRK. ${ }^{11}$ Our study agrees with this finding, because we did not find any significant difference in SIA between LASIK and PRK. However, other studies have reported that induced astigmatism was generally less and more random in axis in LASIK than in PRK. Huang et al noted that flap formation reduces pre-existing corneal astigmatism and produces a relative steepening of the hinge meridian. However, in these studies, the authors used indirect methods to conclude that the flap had induced astigmatism without isolating the contribution of the stromal ablation component, neglecting the possibility that the laser system generated astigmatism even when programmed to perform only a spherical ablation. ${ }^{13-15}$ An additional factor that may affect both PRK and LASIK is the response of the flat versus the steep axis to the spherical ablation in terms of variable healing and differential regression over time. Concerning the magnitude of induced astigmatism, Yi et al reported a mean SIA in myopic eyes of $0.44 \pm 0.38$ (0.00-1.00) at 6 months postoperatively, with mean absolute change in cylinder of $0.39 \pm 0.36(0.00-1.00)$, neither of which are significantly different from the results of our study
$(P=0.137$ and $P=0.829) .{ }^{16}$ Our study provides valuable information for refractive surgeons by comparing vector analysis of PRK and LASIK in eyes treated with myopic spherical ablation in the setting of $<1.00 \mathrm{D}$ of astigmatism.

In our study, the majority of eyes experienced an increase in their cylinder power. Sixteen percent of eyes in the PRK group and $15 \%$ of eyes in the LASIK group had no change in their astigmatic power. In terms of refractive pattern, it was more common to see a spherical pattern change to an astigmatic pattern than an astigmatic pattern change to a spherical pattern. Although the magnitude of increase in cylinder was mainly between $0.50 \mathrm{D}$ and $0.75 \mathrm{D}$, there were four eyes in each group with an increase of $1.00 \mathrm{D}$ or more in their cylinder power ( $6 \%$ for PRK and $6 \%$ for LASIK).

Variation in laser fluence, improper alignment of the optics in the laser, or error in the centration of the mounted microscope may lead to induction of cylinder after spherical ablation. Single zone versus multizone treatments may also have an impact on induction of astigmatism. ${ }^{17}$ In our study, all eyes were treated with an optical zone of $6.5 \mathrm{~mm}$ with blend to $8.0 \mathrm{~mm}$. Saccadic eye movement, rotation of the globe in the supine position during surgery, occasional loss of fixation by the patient, and surgeon error in centration when there may be a significant difference between the center of visual axis and the pupillary center may lead to SIA. Conversely, any minute displacement of the eye, in terms of $x$ or $y$ coordinates with respect to the visual axis, may also induce astigmatism in spherical ablation.

After PRK, the process of irregular healing at the junction of the ablated and untreated cornea, regrowth of the hyperplastic nonuniform epithelium over Bowman's layer with underlying irregularities, and subepithelial deposition of glycosaminoglycans may also contribute to changes in the refractive cylinder after surgery. ${ }^{9,17-20}$ However, in LASIK, epithelial remodeling should not play a role in causing any meridional changes in the surface of the cornea. It is possible that stromal healing at the interface and at the junction of ablated and unablated stroma contributes to the surface changes and induction of astigmatism. However, epithelial changes may also occur, even after LASIK. For example, we know from previous studies with anterior stromal ring implantation of the tendency for the epithelium to increase in thickness in the area surrounding the implant following surgery. Creation of the LASIK flap with the microkeratome compared with the femtosecond laser may also explain the SIA observed in LASIK eyes, although our study was not designed to detect such a difference. Several studies have described decreased SIA in flaps created by the femtosecond 
laser compared with flaps created with a microkeratome. ${ }^{21-25}$ This difference may be due to the differing flap morphologies or to the tissue hydration during flap creation wherein use of a microkeratome requires routine corneal irrigation compared with the relatively dry flap creation with the femtosecond laser. ${ }^{26,27}$

The purpose of this study is realized in providing a vector analysis of induced astigmatism in patients treated with spherical ablation despite preoperative cylinder of $<1.00$ D. Clearly, reporting of visual outcomes in this patient population would provide valuable information to refractive surgeons deciding whether or not to treat the astigmatism, although this was not the purpose of our study, because our focus was primarily one of vector analysis. Knorz et al examined 25 eyes with moderate and high myopia and cylinder $\leq 1.00 \mathrm{D}$ preoperatively that were treated with spherical ablation, and found that $87.5 \%$ of eyes achieved uncorrected visual acuity of $20 / 40$ or better, and $100 \%$ achieved best corrected visual acuity (BCVA) of 20/25 or better at 6 months postoperatively, although their study did not provide vector analysis of SIA. ${ }^{28}$ It may be argued that because the SIA was minimal and the postoperative uncorrected visual acuity and BCVA were not reported in this study that the findings are of minimal clinical significance. However, the purpose of this study was not to provide visual outcomes but was instead to provide an analysis of the change in astigmatism and the axis through Alpins vector analysis, and therein lies its value to the research community. Future studies of SIA in spherical ablation and minimal cylinder should address this by both providing both vector analysis and reporting of postoperative visual outcomes. Several additional weaknesses of this study, must be recognized. LASIK flaps were created with the microkeratome as well as with the IntraLase femtosecond laser, although the vector analysis was not performed comparing each technique; as mentioned, prior studies have examined the differing levels of astigmatism induced with the microkeratome and IntraLasecreated flaps. Given the large time frame of the study, from 2002 to 2012, the laser software underwent several upgrades, and the upgrades could have changed the astigmatic analysis. Finally, several different topography systems were used for the study, which may have introduced confounding factors into the astigmatic analysis even though preoperative and postoperative keratometry measurements were all based on the Atlas corneal topographer.

Overall, our results indicate that refractive surgeons should not disregard even small magnitudes of cylinder in compound myopic astigmatism. The ability to correct astigmatism at the time of excimer ablation for myopia can be an effective approach to treatment of patients with $0.25-0.75 \mathrm{D}$ of cylinder. In addition, implementation of an active eye-tracking system and meticulous attention to centration, laser calibration between each case, lasers with less variance in their fluence, and smoother ablation treatments will help reduce astigmatism and improve visual outcomes.

\section{Conclusion}

In conclusion, spherical ablation can induce significant astigmatic change even in patients with less than a diopter of preoperative astigmatism in both PRK and LASIK, although no difference was found when comparing SIA between PRK and LASIK treatments. The magnitude of SIA increases with increasing preoperative astigmatism in both PRK and LASIK.

\section{Acknowledgment}

This research received funding from the Research to Prevent Blindness Foundation, New York, NY, and the Semnani Family Foundation.

\section{Disclosure}

The authors have no financial interests in any materials or products discussed in this work.

\section{References}

1. Onclinx T, Smith RJ, Maloney RK. Induced astigmatism after photorefractive keratectomy. J Cataract Refract Surg. 1999;25: 183-187.

2. Hersh PS, Abbassi R. Surgically induced astigmatism after photorefractive keratectomy and laser in situ keratomileusis. J Cataract Refract Surg. 1999;25:389-398.

3. Goggin M, Algawi K, O’Keefe M. Astigmatism following photorefractive keratectomy for myopia. J Refract Corneal Surg. 1994; 10:540-545.

4. Shah S, Chatterjee A, Doyle SJ, Bessant DA. Astigmatism induced by spherical photorefractive keratectomy corrections. Ophthalmology. 1997; 104:1317-1320

5. Yang C, Shen E, Hu FR. Laser in situ keratomileusis for the correction of myopia and myopic astigmatism. J Cataract Refract Surg. 2001;27: 1952-1960.

6. Alpins NA. A new method of analyzing vectors for changes in astigmatism. J Cataract Refract Surg. 1993;19:524-533.

7. Alpins NA. New method of targeting vectors to treat astigmatism. J Cataract Refract Surg. 1997;23:65-75.

8. Wu HK. Astigmatism and LASIK. Curr Opin Ophthalmol. 2002;13: 250-255.

9. Simon G, Ren Q, Kervick GN, Parel JM. Optics of the corneal epithelium. Refract Corneal Surg. 1993;9:42-50.

10. Lowenstein A, Lipshitz I, Lichtenstein F, Ben-Sirah A, Lazar M. The effect of spherical photorefractive keratectomy on myopic astigmatism. J Refract Surg. 1995;11 Suppl 3:S263-S264.

11. Sciscio A, Hull CC, Stephenson CG, Baldwin H, O’Brart D, Marshall J. Fourier analysis of induced irregular astigmatism: photorefractive keratectomy versus laser in situ keratomileusis in a bilateral cohort of hyperopic patients. J Cataract Refract Surg. 2003;29:1709-1717. 
12. Seiler T, Holschbach A, Derse M, Jean B, Genth U. Complication of myopic photorefractive keratectomy with the excimer laser. Ophthalmology. 1994;101:153-160.

13. Pallikaris IG, Kymionis GD, Panagopoulou SI, Siganos CS, Theodorakis MA, Pallikaris AI. Induced optical aberrations following formation of a laser in situ keratomileusis flap. J Cataract Refract Surg. 2002;28:1737-1741

14. Hersh PS, Abbassi R. Surgically induced astigmatism after photorefractive keratectomy and laser in situ keratomileusis; Summit PRK-LASIK Study Group. J Cataract Refract Surg. 1999;25: 389-398.

15. Huang D, Sur S, Seffo F, Meisler DM, Krueger RR. Surgically-induced astigmatism after laser in situ keratomileusis for spherical myopia. $J$ Refract Surg. 2000;16:515-518.

16. Yi DH, Petroll M, Bowman RW, McCulley JP, Cavanagh HD. Surgically induced astigmatism after hyperopic and myopic photorefractive keratectomy. J Cataract Refract Surg. 2001;27:396-403.

17. Shieh E, Moreira H, D’arcy J, Clapham TN, McDonnell PJ. Quantitative analysis of wound healing after cylindrical and spherical excimer laser ablations. Ophthalmology. 1992;99:1050-1055.

18. Wu WC, Stark WJ, Green WR. Corneal wound healing after 193-nm excimer laser keratectomy. Arch Ophthalmol. 1991;109:1426-1432.

19. Binder PS. What we have learned about corneal wound healing from refractive surgery. Refract Corneal Surg. 1989;5:98-120.

20. Hersh PS, Shah SI, Geiger D, Holladay JT. Corneal optical irregularity after excimer laser photorefractive keratectomy. $J$ Cataract Refract Surg. 1996;22:197-204.

21. Kezirian GM, Stonecipher KG. Comparison of the IntraLase femtosecond laser and mechanical keratomes for laser in situ keratomileusis. J Cataract Refract Surg. 2004;30:804-811.
22. Tran DB, Sarayba MA, Bor Z, et al. Randomized prospective clinical study comparing induced aberrations with IntraLase and Hansatome flap creation in fellow eyes: potential impact on wavefront-guided laser in situ keratomileusis. J Cataract Refract Surg. 2005;31:97-105.

23. Stonecipher KG, Kezirian GM. Wavefront-guided and optimized treatments with keratectomies using the Moria disposable and the Intralase $30 \mathrm{kHz}$ FS keratome. Presented at the 2005 meeting of the European Society of Cataract and Refractive Surgeons, September 10-14, Lisbon, Portugal.

24. Stonecipher K, Ignacio TS, Stonecipher M. Advances in refractive surgery: microkeratome and femtosecond laser flap creation in relation to safety, efficacy, predictability, and biomechanical stability. Curr Opin Ophthalmol. 2006;17:368-372.

25. Muñoz G, Albarrán-Diego C, Ferrer-Blasco T, García-Lázaro S, Cerviño-Expósito A. Long-term comparison of corneal aberration changes after laser in situ keratomileusis: mechanical microkeratome versus femtosecond laser flap creation. J Cataract Refract Surg. 2010;36:1934-1944.

26. Kim WS, Jo JM. Corneal hydration affects ablation during laser in situ keratomileusis. Cornea. 2001;20:394-397.

27. Dougherty PJ, Wellish KL, Maloney RK. Excimer ablation rate and corneal hydration. Am J Ophthalmol. 1994;118:169-176.

28. Knorz MC, Wiesinger B, Liernann A, Seiberth V, Liesenhoff H. Laser in situ keratomileusis for moderate and high myopia and myopic astigmatism. Ophthalmology. 1998;105:932-940.
Clinical Ophthalmology

\section{Publish your work in this journal}

Clinical Ophthalmology is an international, peer-reviewed journal covering all subspecialties within ophthalmology. Key topics include: Optometry; Visual science; Pharmacology and drug therapy in eye diseases; Basic Sciences; Primary and Secondary eye care; Patient Safety and Quality of Care Improvements. This journal is indexed on

Submit your manuscript here: http://www.dovepress.com/clinical-ophthalmology-journal

\section{Dovepress}

PubMed Central and CAS, and is the official journal of The Society of Clinical Ophthalmology (SCO). The manuscript management system is completely online and includes a very quick and fair peer-review system, which is all easy to use. Visit http://www.dovepress.com/ testimonials.php to read real quotes from published authors. 